\title{
ANÁLISIS DE LAS DECISIONES ESTRATÉGICAS: CASO UNE EPM TELECOMUNICACIONES*
}

\author{
ALICIA MILLÁN VILLANUEVA**, IVÁN MONTOYA RESTREPO*** \& LUZ ALEXANDRA MONTOYA RESTREPO***** \\ UNIVERSIDAD NACIONAL DE COLOMBIA
}

Recibido/ Received/ Recebido: 31/03/2014 - Aceptado/ Accepted / Aprovado: 29/08/2014

\begin{abstract}
Resumen
El objetivo de este artículo es identificar la presencia de ciertos patrones en la formación de la estrategia de la empresa UNE EPM Telecomunicaciones, que han influido en la toma de decisiones. Los referentes teóricos son básicamente tres: Ansoff, Porter y Mintzberg. El análisis se centra en una serie de comparaciones y coincidencias entre la teoría y los hallazgos encontrados, en lo que respecta a comportamientos, resultados y decisiones de la compañía, de donde se logra vislumbrar la estrategia adoptada.
\end{abstract}

Palabras clave: Formación de la estrategia, Toma de decisiones, Patrones, Flujo de decisiones.

\section{ANALYSIS OF STRATEGIC DECISIONS: CASE OF UNE EPM TELECOMMUNICATIONS}

\begin{abstract}
The objective of this article is to identify the presence of certain patterns in the formation of the strategy of the UNE EPM Telecommunications business that have influenced the decisions making. The theoretical references are basically three: Ansoff, Porter and Mintzberg. The analysis was centered in the series of comparisons and coincidences between the theory and the findings, related to behaviors, results and decisions of the company from which it's possible to glimpse the adopted strategy. Keywords: Strategy formation, Decision making, Patterns, Flow-making.
\end{abstract}

* Artículo de investigación dentro del marco del Grupo de Investigación en Mercados, Innovación y Competitividad en Gestión Agropecuaria (MILAGRO), Universidad Nacional de Colombia.

**: Ingeniera Electrónica, Institución Universitaria de Envigado. Especialista en Redes Corporativas, Universidad San Buenaventura. Estudiante de Maestría Ingeniería Administrativa, Universidad Nacional de Colombia. E-mail: amillanv@gmail.com. Tel: (57) (4) 515 7982. Dirección postal: Cll. 78 Sur \# 40 - 211 apto 2305, Medellín (Colombia).

**** Administrador de empresas, Magister en Administración, Doctor en Ciencias Económicas, Profesor Asociado Universidad Nacional de Colombia sede Medellín, E-mail: iamontoyar@unal.edu.co Tel: (57) (4) 6902540. Dirección postal: Cll. 47 DD \# 87-4 apto 604, Medellín (Colombia).

***** Administradora de empresas, Magister en Administración, Doctora en Ciencias Económicas, Profesora Asociada Universidad Nacional Colombia sede Medellín, E-mail: lamontoyar@unal.edu.co Tel: (57) (4) 5157982 . Dirección postal: Cll. 47 DD \# 87-4 apto 604, Medellín (Colombia). 


\title{
ANÁLISE DAS DECISÕES ESTRATÉGICAS: CASO UNE EPM TELECOMUNICAÇÕES
}

\section{Resumo}

\begin{abstract}
O objetivo deste artigo é identificar a presença de certos padrões na formação da estratégia da empresa UNE EPM Telecomunicações, que influenciaram as decisões tomadas. Os referentes teóricos são basicamente três: Ansoff, Porter e Mintzberg. A análise centra-se em uma série de comparações $e$ coincidências entre a teoria e os resultados encontrados, no que diz respeito a comportamentos, resultados e decisões da companhia, de onde se consegue vislumbrar a estratégia adotada.
\end{abstract}

Palauras chave: Formação da estratégia, Decisões tomadas, Padrões, Fluxo de decisões.

Millán, A., Montoya, I. \& Montoya, L. (2015). Análisis de las decisiones estratégicas: caso une EPM Telecomunicaciones. En: Revista de la Facultad de Ciencias Económicas de la Universidad Militar Nueva Granada. rev.fac.cienc.econ, XXIII (1).

JEL: M10, M19.

\section{Introducción}

Dados los procesos de cambio en UNE EPM Telecomunicaciones S.A. en adelante UNE, resulta de interés identificar la presencia de ciertos patrones en la formación de su estrategia, que a su vez han influido en la constante toma de decisiones, promoviendo cambios significativos durante sus 6 años de formación, lo cual se evidencia en los cambios propuestos dentro de la historia corporativa:

"En el año 2005, Empresas Públicas de Medellín, después de observar el entorno, analizar las señales de los clientes y determinar las posibilidades del negocio, replanteó el mercado de servicios públicos domiciliarios y configuró tres grupos estratégicos de negocio: Energía, Aguas y Telecomunicaciones. Cada uno muy diferente del otro, con dinámicas competitivas distintas y retos específicos.

Para cumplir entonces con la estrategia definida por EPM, el primero de julio de 2006 se escinde la UEN Telecomunicaciones, dando origen a EPM Telecomunicaciones S.A. con su marca UNE. Así, queda constituida como una empresa $100 \%$ pública, propiedad de Empresas Públicas de Medellín, conformada como una sociedad anónima por acciones, que presta servicios de tecnologías de información y comunicaciones a sus clientes en todo el país.

Al igual que para los otros negocios de EPM (Aguas y Energía), para UNE se definió una Meta Estratégica Grande y Ambiciosa (MEGA) a largo plazo que debe cumplir en el 2015.

«Al 2015, UNE será la empresa integrada de telecomunicaciones más competitiva de Colombia, y emergentemente sirviendo la comunidad de la diáspora latinoamericana en USA y España; con ingresos por ventas equivalentes a US\$1.500 millones, con una tasa de crecimiento interanual por encima de la industria y con un EBITDA creciente respecto al resultado del año anterior. Como referencia para el logro de la MEGA al 2015, se espera que al 2011 los ingresos por ventas sean de US\$ $1.185 \mathrm{mi}$ llones».

Atendiendo a los imperativos estratégicos definidos por EPM, el primero de agosto de 2007 se produce la integración operativa, comercial y organizacional con Orbitel y parte del patrimonio escindido de Emtelco, empresas $100 \%$ propiedad de UNE. Para 
continuar con el proceso de consolidación nacional, UNE compra el porcentaje de participación que le hacia falta para ser dueños $100 \%$ de Emtelsa en Manizales, adquiere las cableras Promisión de Bucaramanga y Costavisión de Cartagena e integra comercialmente las filiales de telecomunicaciones". ${ }^{1}$

Es así como, en el cambiante sector de las telecomunicaciones debido a la innovación tecnológica, la toma de decisiones puede marcar o no algunas estrategias, favoreciendo o desvirtuando la diferenciación con sus competidores.

La conformación de UNE como una entidad independiente después del desmembramiento de EPM, ha originado una serie de cambios estructurales $y$ metodológicos que pueden haber sido o no rentables y estratégicos ${ }^{2}$, causando a su vez impactos positivos o negativos sobre sus resultados.

Con este artículo se muestra un estudio de las principales definiciones estratégicas, dadas por autores reconocidos $^{3}$, tomando sus investigaciones como base para analizar los patrones que se han seguido en el flujo y toma de decisiones en la empresa que es objeto del estudio de este documento. Se termina con una crítica de los principales cambios en el desarrollo de la organización con respecto a lo evidenciado del análisis anterior.

De igual forma se podrá encontrar los aspectos más relevantes resultado de alguna estrategia propuesta, cambio estructural $e$ incluso decisiones, para luego identificar aquellos patrones que resultan en la agrupación por ciclos anuales, que finalmente muestran las estrategias claras demarcadas en cada periodo. El objetivo fundamental de este trabajo es evaluar las tendencias estratégicas más significativas desarrolladas a través de los años y analizar su impacto con respecto a los resultados de la compañía desde su conformación hasta el 2013.

\section{Marco teórico}

Tomar las mejores decisiones a nivel administrativo, conlleva por sí mismo el asumir riesgos que pueden marcar la diferencia en cuanto al éxito o fracaso empresarial.

El estudio de las estrategias, la toma de decisiones y la gran variabilidad que se ha tenido en UNE, revela de alguna forma caracteres especiales de los siguientes tres autores, sobre los cuales se describe la teoría que más valor aporta en el desarrollo de este trabajo, para finalmente aplicarlo en un momento determinado de la compañía.

Siguiendo la temática en cuestión, los autores más relevantes a desarrollar son:

\subsection{Ansoff}

Para Ansoff (1957) y Ansoff, Declerk \& Hayes (1983) la competencia no se da en términos de toda la organización o en todo el mercado, la competencia se da en productos específicos y mercados específicos, lo que para la estrategia competitiva radicaría en la búsqueda de conocer cuales productos compiten y en cuales mercados específicamente.

Ansoff (1957) en su artículo "Strategies por diversification" menciona cuán importante es el posicionamiento de una compañía en el sector, tanto, que su crecimiento y cambio deben ser tan rápidos como pueda, o lo que menciona Montoya (2010), como una organización de unidades estratégicas de negocios, agrupando servicios o productos, que a su vez, llegan a compartir clientes y competidores. Esta forma de crecimiento puede realizarse incrementando su penetración en el mercado, innovando en el desarrollo de productos, o diversificando.

1 Historia de UNE EPM Telecomunicaciones, extraída de: http://www.une.com.co/pymes/foro/2-bienvenidos/141-logo-firmy-budowlanej.html

2 Ver Anexo 1 con las notas de prensa sobre el tema.

3 Se identifica a Mintzberg como un autor importante, con teorías y conceptos clave en la búsqueda de patrones e identificación de flujo de decisiones. Sin embargo, una vez se comenzó con el análisis de la información de UNE EPM Telecomunicaciones, se hizo relevante mostrar los planteamientos de autores como Ansoff y Porter, con los cuales se logró realizar un comparativo entre sus aportes y algunas decisiones o cambios identificados en periodos anuales. 
Diversificación de acuerdo a la definición dada: "es usualmente asociada con un cambio en las características de la línea de la compañía, producto o mercado, en contraste con la penetración y desarrollo de mercado y/o productos" (Ansoff, 1957).

El hecho en sí de diversificación puede darse por muchos motivos, Ansoff, Declerk \& Hayes (1983) describen como la compensación de la obsolescencia tecnológica, para distribuir algún tipo de riesgo, obtener una alta administración, pero cualquiera que sea este, debe analizar su estrategia y las proyecciones de su crecimiento; mencionan además algunos de estos métodos de proyección.

Una vez los resultados arrojan la confirmación que es posible y se debe realizar la diversificación, Ansoff (1957) sugiere tres métodos:

- Vertical: que consiste en diversificar su actividad a la producción de componentes, piezas y materiales.

- Horizontal: introducción en nuevos productos

- Lateral: invita a ir a la empresa más allá de sus posibilidades e incluso de la industria a la cual pertenece (Martinet, 2010; Moussetis, 2011).

De a acuerdo con Ansoff (1957) el paso siguiente es escoger cuál estrategia y bajo qué método de calificación se utilizaría:

- Cualitativa: comparando la oportunidad de diversificación individual con la diversificación de objetivos.

- Cuantitativa: con las diferentes técnicas existentes para predecir que se tienen.

En resumen, Ansoff (1957) propone realizar un estudio acerca de producto y mercado, de donde surgen los siguientes conceptos:

- Un producto específico para un tipo de mercado específico se conoce como penetración de mercado.
- El desarrollo de producto se centra en analizar nuevo producto para un mismo mercado,

- Y por último la búsqueda de nuevos mercados para un producto existente, se conoce como desarrollo de mercado.

- En el caso de productos nuevos para mercados nuevos se toca un tema de diversificación (Ansoff \& McDonnell, 1990).

En este orden de ideas, el aporte de Ansoff para este trabajo se centra en las cuatro principales estrategias corporativas, donde se define en cuáles mercados se va a competir y con qué productos, el cual se podrá identificar en el siguiente apartado.

\subsection{Porter}

Porter (1980, 1990, 1991) difiere con la teoría de Ansoff (1957), ya que para él dichos aportes se aplican muy bien sobre mercados en crecimiento. Sin embargo después de las crisis económica de los 70's, los factores de mercado cambian: hay muchos queriendo vender y pocos comprar, es entonces cuando el problema radica en buscar la forma de recuperar la inversión lo suficientemente rápido frente a la inversión tecnológica realizada y con cual tamaño de mercado se puede lograr. En este punto los competidores cobran un papel importante en la búsqueda de productos sustitutos que satisfagan las necesidades del usuario sin importar siquiera si se encuentran en el mismo sector o no.

Es cuando Porter (1991) en su artículo "Towards a dynamic theory of strategy" propone una teoría dinámica identificando el éxito o fracaso una organización, partiendo de una base de conocimiento de sí misma y de su importancia en la participación sobre la industria, así como su posición relativa en la misma. Tomando este legado se tiene:

- La estructura de la industria está dado por las 5 fuerzas de Porter ${ }^{4}$ que arrojan finalmente un diagnóstico de referencia actual.

4 Las 5 fuerzas de Porter $(1980,1990)$ son: i) poder negociador de los compradores; ii) poder negociador de los proveedores; iii) amenaza de entrada de nuevos competidores; iv) amenaza de ingreso de productos sustitutos; v) rivalidad interna de la industria entre competidores. 
- Su posición relativa buscando una ventaja competitiva sostenible.

- La importancia del alcance al realizar comparaciones entre organizaciones, observando las capacidades y comportamientos entre competidores (Porter, 1980, 1990, 1991; Porter \& Kramer, 2011).

Con base en estas dimensiones es que según Porter (1991) se puede tomar decisiones, lo que resume finalmente una estrategia. La cual estaría definida por tres líneas de investigación:

- Teoría del juego: teoría dinámica con base en la interacción estratégica entre competidores

- Compromiso bajo la incertidumbre: se determina a través de la construcción de escenarios, comportamiento de decisiones y psicología cognitiva.

- $\quad$ RBV (recursos con base en el punto de vista de la organización): nuevos recursos hacen posibles nuevas actividades, permitiendo que estos sean complementos en el crecimiento y ventaja competitiva de la organización.

Lo anterior se consolida en el diamante de Porter, el cual define la competitividad de una organización en 4 atributos fundamentales: competidores potenciales, sustitutos, compradores, proveedores.

Montoya (2010) desarrolla la formación de la estrategia en su enfoque racional, es decir como aquel proceso formal de planeación, diseño y posicionamiento, según este estudio realizado en una de las propuestas más célebres de posicionamiento, "la intención primordial de Porter es establecer la razón por la cual algunas empresas son exitosas y otras fallan", encontrando que este éxito depende de la posición competitiva de dichas empresas en el sector, cuyas razones siguiendo a Porter (citado por Montoya, 2010) podrían ser:

- Solución al problema de agencia: estrategia entendida como elemento integrador de las actividades de cada división de la empresa.
- Armonización de elementos externos e internos: estrategia entendida como el acto de alinear una compañía con el ambiente en el cual se desempeña; los objetivos y reglas internas de una firma deben guardar correspondencia con las oportunidades y los tratados hechos en la industria.

- Creación de competencias distintivas: estrategia entendida como el desarrollo de técnicas, procesos o productos diferentes que permitan el posicionamiento competitivo de una firma (Porter \& Kramer, 2011).

Sin embargo, hace falta complementar dichas razones con los dos componentes que según Porter (1991) son fundamentales en el desarrollo de la estrategia:

- Efecto industria: explicado en su modelo de las 5 fuerzas.

- Efecto posicionamiento: describe la posibilidad de tener beneficios excepcionales con respecto a sus competidores, dividiendo su estrategia a lo que él llama actividades (escala, localización, integración vertical, regulación, antigüedad, etc.).

De modo que la ventaja competitiva no se entiende según Porter (1990), considerando la compañía como un todo, por el contrario es en la cadena de actividades que una empresa realiza para dar valor a sus clientes, en palabras de Montoya (2010) es: "logística de entrada, operaciones, logística de salida, mercadeo, ventas y servicio; acompañada de 4 actividades de apoyo que son compras, desarrollo de tecnología, gestión de recurso humanos e infraestructura de la empresa".

Así mismo Montoya (2010) define las estrategias genéricas de posicionamiento, según el enfoque dado por Porter (1991), en donde se puede determinar la ganancia o perdida de recursos, limitados por el sistema que llevaran a la mejora del agente $e^{5}$ en procesos adaptativos, de desempeño y tamaño.

\footnotetext{
5 Montoya (2010) describe al agente (en el marco de los sistemas complejos adaptables) como aquel elemento activo, que opera acorde con la noción de sistema, lo que le permite desarrollar su capacidad de adaptación al entorno.
} 
Es decir, la matriz de posicionamiento según Porter (1991) consiste en tener una posición sobre la que se pueda evitar tener competencia de dos formas: convirtiéndose en el líder absoluto en costos sobre una industria, o teniendo una propuesta diferenciadora, o utilizando una combinación entre las dos anteriores: calidad/servicio $v s$. precio.

Montoya (2010) sin embargo en su tesis doctoral, menciona las principales críticas al enfoque de Porter resumidas en la Ilustración 1.

Ilustración 1. Críticas al enfoque de Porter ${ }^{6}$

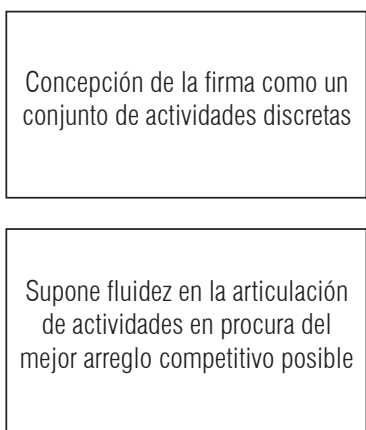

Concepción epistemológica del problema de desempeño de la firma asociado al modelo conducta- estructura- desempeño.

La existencia de mecanismos de integración empresarial cuestiona la utilidad de la combinación de actividades en la ejecución de la estrategia.

\subsection{Mintzberg}

Sin embargo, la propuesta de Porter no contempla la toma de decisiones en momentos de innovación o cambios, su teoría es fácilmente adaptable en procesos deliberados en donde la estrategia es planeada, anticipada, ejecutada, como parte de un proceso formal, racional y sobre la cual se "espera" tener buenos resultados, pero ¿cómo se puede identificar si realmente una estrategia es buena o no, antes de ser ejecutada? Es donde precisamente Mintzberg (1984, 1987, 1990, 2009, 2012) se cuestiona al identificar aquellas situaciones que no han sido planeadas sino que en el camino se fueron realizando, es decir las estrategias emergentes.

Mintzberg (1978) define entonces una estrategia particular como "un patrón en un cadena de decisiones" las cuales pueden surgir entre ambientes dinámicos y

momentos burocráticos. Sin embargo, se puede llegar a construir una estrategia a través de un proceso consciente antes de que la misma decisión sea ejecutada o también se puede formar gradualmente e ir tomando las decisiones una a una.

De acuerdo con Mintzberg (1978), él sugiere una metodología divida en 4 grupos de estudio:

- Colección de datos básicos: consiste en escoger cuales eventos de estudio y cuales decisiones tomadas en el pasado son significativas de revisar, la información puede ser extraída de revistas, reportes de periódicos, catálogos, entrevistas, etc.

- Interferencia de las estrategias y períodos de cambio: estas estrategias pueden ser comparadas entre sí definiendo grupos de comparación, por ejemplo entre áreas para identificar ciertos periodos claves en el proceso (flujo, cambio global, continuidad, cambios minoritarios, agrupaciones, etc.).

- Análisis intensivo de los periodos de cambio: se deja a un lado la percepción general para entrar a analizar los informes en profundidad.

- Análisis teórico: se comienza a realizar hipótesis para explicar lo encontrado.

De último, la formación de la estrategia, después de identificar claramente sus periodos y tener formadas las hipótesis, puede ser vista como:

- Aquellas que pueden surgir entre ambientes dinámicos y momentos burocráticos.

- Los periodos ayudan a seguir distintas regularidades las cuales permiten comprender el proceso.

- El estudio entre la interacción de las estrategias deliberadas y las realizadas pueden llevarnos al proceso organizacional.

En resumen, la formación estratégica puede ser vista con base en la interacción de las tres principales fuerzas como se muestra en la Ilustración 2.

$6 \quad$ Fuente: Montoya $(2010,26)$. 
llustración 2. Formación de la estrategia ${ }^{7}$
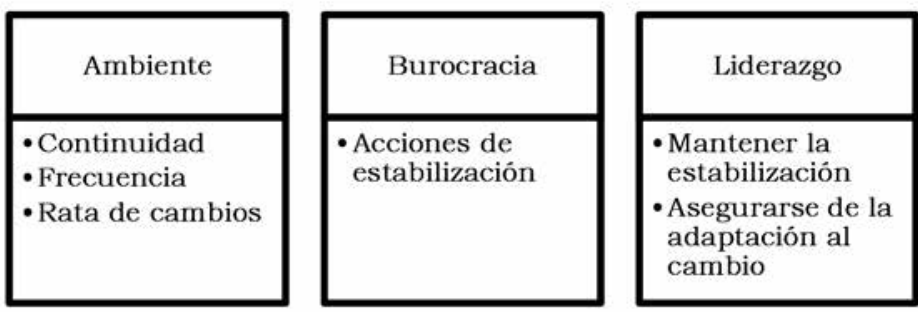

Aunque no se puede predecir un periodo de tiempo para que una organización tome o no una estrategia -ya que pueden pasar años, décadas para que pase por alguno de los estados anteriormente definidos-, Mintzberg (1978) define dos patrones particulares: i) el ciclo de vida de una estrategia general; y ii) la presencia de ondas periódicas de cambios y continuidad dentro del ciclo de vida.

Esto es lo que precisamente da una entrada al análisis de los tipos de estrategias que se pueden encontrar (Ilustración 3).

Respecto a las estrategias intencionadas, Mintzberg (1978) afirma que:

“(...) logran ser realizadas son llamadas estrategias deliberadas; las estrategias inten- cionadas que no logran realizarse debido a sus expectativas poco realistas, juicios equivocados del ambiente, o cambios incluso en su implementación son llamadas estrategias no realizadas; las estrategias realizadas que nunca fueron estrategias deliberadas tal vez porque no se tenía una estrategia como objeto o porque fueron desplazadas a lo largo del camino son llamadas estrategias emergentes".

Las apreciaciones de Mintzberg (1978), con respecto a la relación entre una estrategia emergente y una estrategia deliberada se encuentran relacionadas en la acumulación de experiencias, siguiendo posiblemente una serie de patrones y perspectivas que podrían llegar a tener incidencia sobre las instancias de poder.

Ilustración 3. Tipos de estrategias ${ }^{8}$

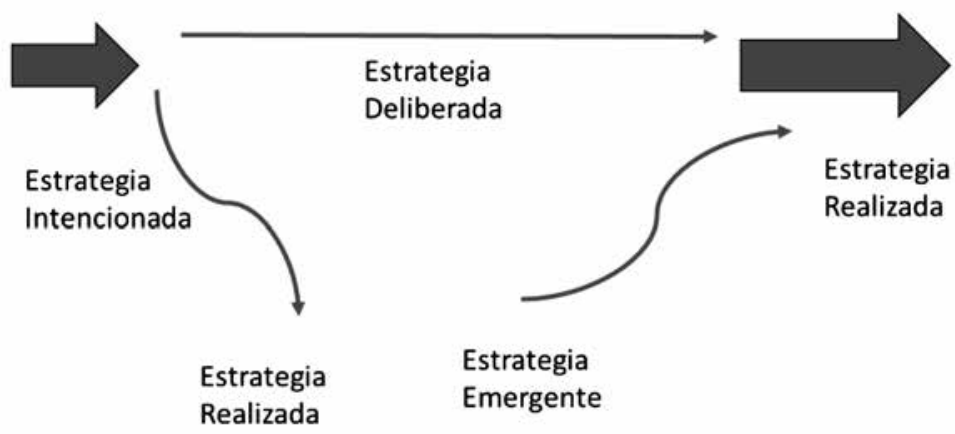

7 Fuente: Elaboración propia a partir de Mintzberg (1978).

8 Fuente: Mintzberg $(1978,945)$. 
Las estrategias no son planes organizados ni es un cambio sistemático a seguir gradualmente por aquellos quienes tomas las decisiones. Según Mintzberg (1978) el modelo de adaptación de las empresas produce una noción dinámica y de carácter evolutivo permitiendo profundizar en cortes de proceso cognitivo. De hecho las causas que permiten identificar las acciones buscan tener consecuencias favorables para la organización en su industria y con respecto a la competencia.

Conforme a lo que expone Mintzberg (1984) las organizaciones pueden ser categorizadas desde dos puntos de vista: de acuerdo con aquellos a quien se debe servir, y en términos de cómo lograr el control sobre sus miembros (y su forma de participación)

Los tipos de configuración de poder en la organización descritas por Mintzberg (1984) son:

- El instrumento: los servidores dominantes de la organización están influenciados por factores externos. Generalmente la organización es burocrática, con un control personalizado de liderazgo e ideologías fuertes.
- Sistema cerrado: internamente es burocrática y externamente pasiva. Los administradores por si mismos tienen un balance de poder, influenciados por factores externos para ayudar al crecimiento.

- Autocrática: externamente es pasiva, utilizando un poder de liderazgo personal.

- Misionera: dominada por una ideología interna fuerte, con fuertes creencias internas.

- Meritocrática: orientada a una experticia técnica, el control burocrático es mínimo

- La arena política: es caracterizada por los conflictos internos resultado de un bajo nivel de poder y división externa.

Sin embargo, un modelo de ciclo de vida debería seguir una secuencia desde el establecimiento mismo de las organizaciones, concluyendo en su investigación a cuatro estados finales: formación, desarrollo, madurez, declinación.

Mintzberg (1984) describe claramente cada uno de los estados y la relación entre ellas para su hipótesis, sin embargo también define que la gran mayoría de las organizaciones pasan a través de estos estados

Ilustración 4. Modelo de organización en el ciclo de vida9

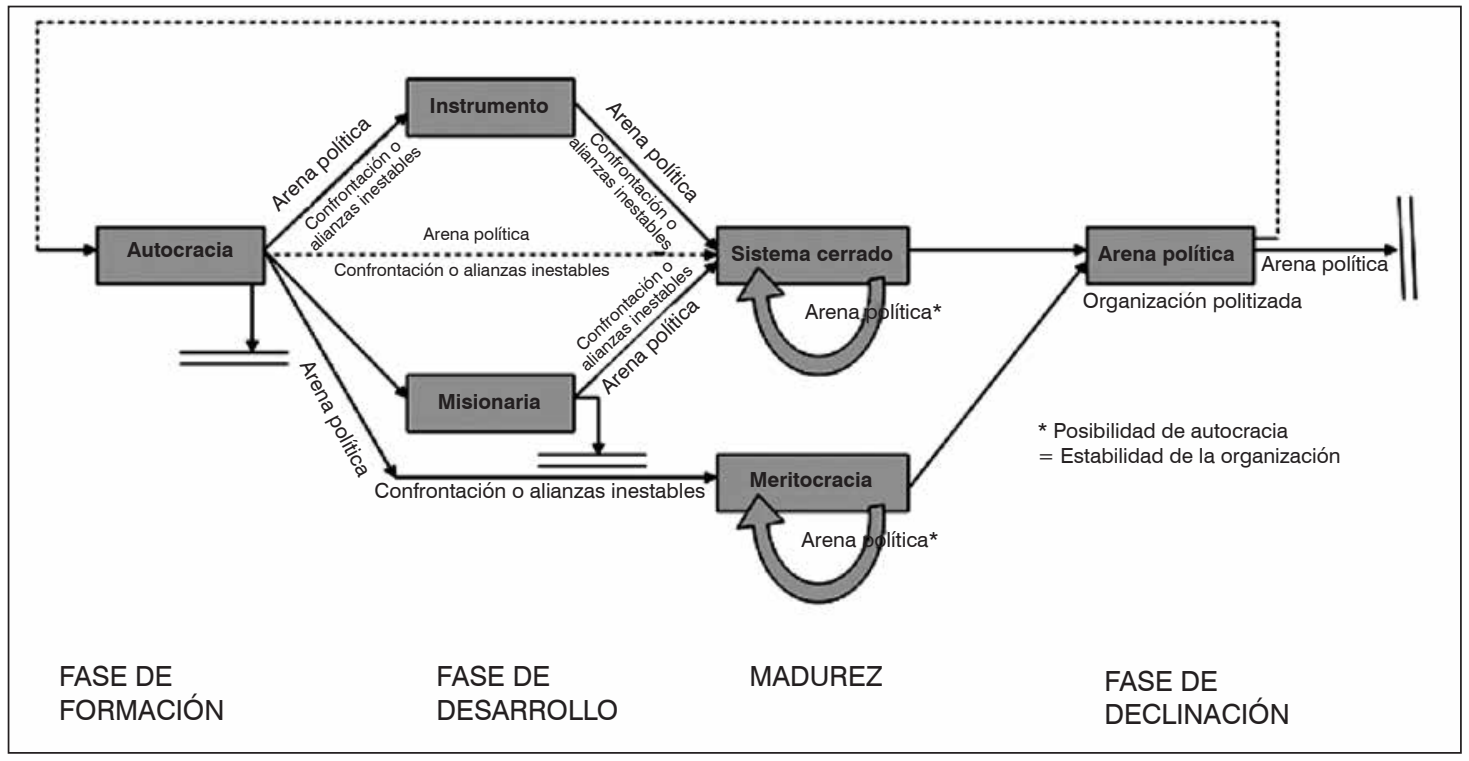

9 Fuente: Montoya (2009, 35), quien lo adapto de Mintzberg (1984). 
en cualquier momento, siendo alguno de ellos más destacado que los otros.

De otro lado, Mintzberg (1987) presenta cinco definiciones de estrategia, así como la relación entre ellas, como sigue:

- Equivalente a un plan, logrando ser una guía para interactuar sobre una situación. La estrategia entonces puede tener dos características, la primera en donde puede realizarse tomando ventaja de las acciones sobre las cuales fue aplicada o si ellas fueros desarrolladas conscientemente para un propósito.

- Un patrón que se convierte en una conducta predeterminada a través del tiempo ejecutando una cadena de acciones, los cuales pueden aparecer diferentes de un plan sin ninguna preconcepción ${ }^{10}$.

- Un patrón generalmente se enfoca en la decisión ${ }^{11}$, siendo ésta un ordenamiento de recursos (Montoya, 2010) que utiliza factores internos y externos, cuyo énfasis en el modelo evolutivo planteado por el autor, el agente logra aprender de sus expectativas y transferir a sus marbetes ${ }^{12}$ de ataque y defensa aquellos que puedan ser viables a su propia adaptación.

- Como una posición frente a su entorno y la relación con sus competidores, generando valor económico para la organización. Nótese de igual forma que podría llegar a existir una relación con las dos anteriores, ya que una posición puede darse a través de un plan o incluso a través de un patrón de comportamientos.

- Una perspectiva que orienta y proporciona coherencia, con una mirada hacia el interior de la organización.
- Explicita desarrollada y ejercida con una intención para anticiparse a una decisión.

Aunque siempre existirá una relación entre ellas, también Mintzberg (1987) manifiesta que puede no existir ninguna, pero lo que sí es claro es que de alguna manera se complementan: "No todos los planes se vuelven patrones, no todos los patrones se pueden desarrollar según lo planeado, algunas tácticas son menos que posiciones, mientras que otras estrategias logran ser más que posiciones alcanzando ser perspectivas. Cada definición agrega un elemento importante a nuestra comprensión de la estrategia, de hecho nos anima a abordar preguntas fundamentales acerca de la organización en general".

En Montoya \& Montoya (2003) se menciona el direccionamiento estratégico, como aquel que puede centrarse desde la coordinación hacia la toma de decisiones, y destacando a autores como Chekland se llega al problema del pensamiento estratégico como "holones" o a un "todo" con propósito definido.

Una primera presunción de ese objeto de estudio ${ }^{13}$ es la toma de decisiones en una organización, y estas a su vez consideran la combinación de elecciones, que le permiten a la organización modificar su posición competitiva de acuerdo al entorno en el que se encuentren para sobrevivir.

Es como se concluye, un punto de partida de estudio la organización relacionada con la toma de decisiones estratégicas. En este punto existen aportes de la literatura sobre economía de la organización, la teoría clásica y contemporánea. Montoya (2009) en su recorrido ilustra las principales teorías, expositores de la época y posteriores, con real importancia dentro de la investigación propuesta en este documento.

10 Montoya (2010) enuncia claramente los tipos de estrategias, según lo propuesto por Mintzberg (1984) y otros autores más en la literatura: i) Estrategia intencionada: con intensión precisa en la organización, común a todos los autores, y debe haberse realizado tal y como se propuso. ii) Estrategia emergente: proceso incremental de prueba y error, que sigue una serie de patrones, generando una acción sin intención.

11 Desde el enfoque evolutivo, una decisión es un compromiso de recursos para la realización de una acción y que condensa una red de causalidades percibidas del agente (Montoya, 2010).

12 Para Holland citado por Montoya (2010), los marbetes facilitan y dirigen transacciones.

13 Considerar enfoque metodológico de la llustración 5 para el estudio del pensamiento estratégico como "holones". 
Ilustración 5. Despliegue del enfoque metodológico ${ }^{14}$

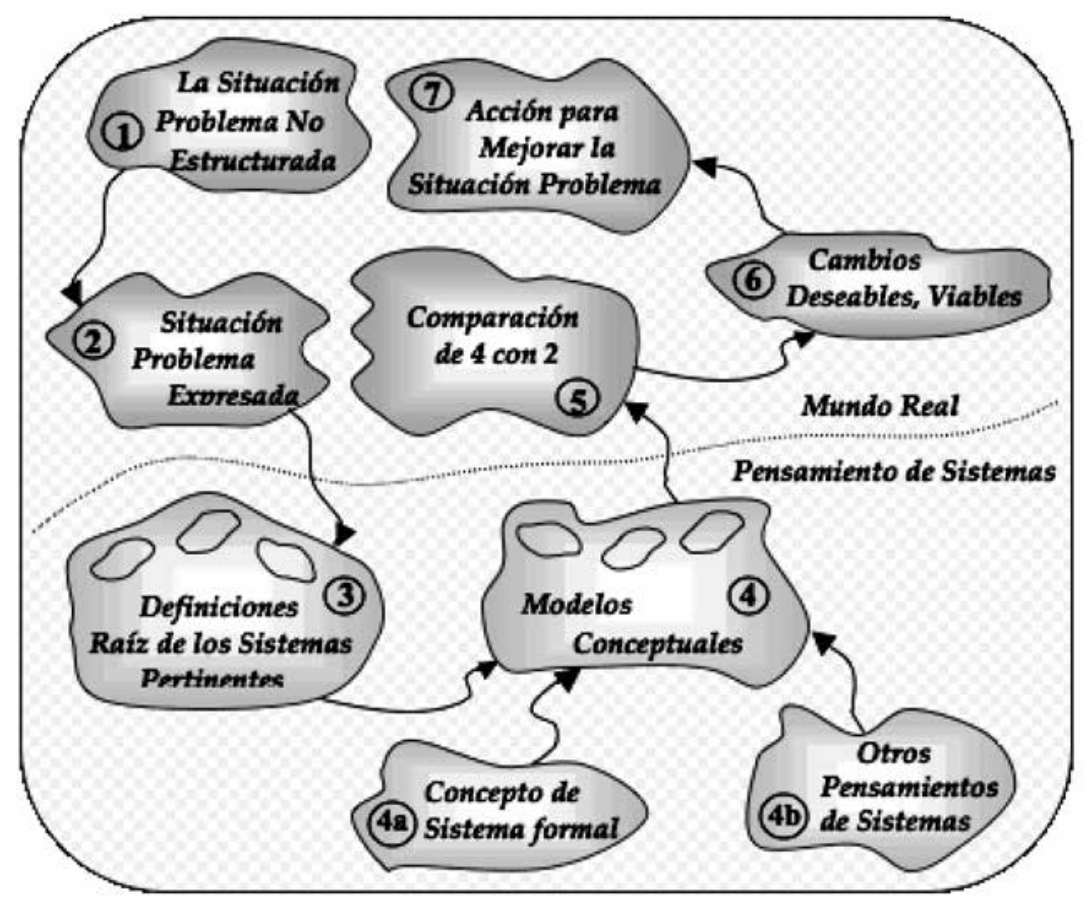

De modo que las organizaciones son creadas según (Montoya \& León, 2004):

“(...) como resultado de la obligación de satisfacer necesidades existentes en la sociedad. Se constituyen entonces con el objetivo de transformar los recursos en productos y/o servicios que brinden satisfacción a sus clientes. Sin duda alguna para que una empresa sea exitosa, deberá emplear nuevos modelos de negocios en los que la innovación sea radical y constante. Tanto a nivel macro como micro se hace necesario cambiar de estrategia, definir la visión y misión y construir las bases para lograr verdaderas ventajas competitivas".

Esto abre las puertas para la investigación en gerencia de la innovación cuyo centro de atención son los productos, procesos, servicios y activos (Montoya \& León, 2004). Aquellos que se deben modificar según Beltrán citado en el mismo artículo son:
- Usuario o cliente: sus necesidades y expectativas definen las características del producto que la organización producirá para él.

- Producto: es la traducción de las necesidades del cliente en especificaciones.

- Proceso: etapas para transformar la materia prima en el producto deseado y generalmente incluye los procesos de apoyo, gerencial y operativo.

- Recurso: provee a la organización los insumos de calidad, cantidad, el momento y la forma óptima para su transformación.

Sin embargo Mintzberg (1984) propiamente no concibe la estrategia como algo explicito, por el contrario, de acuerdo a Montoya (2010), Mintzberg argumenta que "tal definición es incompleta para la organización y no es operacional para el investigador". Y lo que finalmente podría formar una estrategia seria una secuencia de decisiones consistentes en el tiempo, lo que complementa Montoya (2010) con la estrategia evolutiva, creando mecanismos de

14 Fuente: Ortiz $(2013,1)$. 
aprendizaje por ensayo y error, o aprendizaje por representaciones anticipadas, redefinidas a partir de la retroalimentación.

Pero finalmente, ¿qué es una decisión? Según Montoya (2010) "son compromisos de recursos para la realización de una acción y que condensan una red de causalidades percibidas del agente", mientras que para Mintzberg (1978) es "un compromiso hacia la acción".

Lo anterior permite pensar que los agentes puedan anticipar los resultados de sus acciones, según el modelo propuesto por Montoya (2010) con el ciclo entre estrategias deliberadas y emergentes.

Siguiendo entonces la línea de investigación ya mencionada por Montoya (2010), Mintzberg (1990) clasifica una formación estratégica en el campo administrativo, que también cuenta con ciertos enfoques y de los cuales realiza simultáneamente sus propias críticas:

- Planeación y posicionamiento: siguiendo premisas de pensamiento de consciente, estrategias simples, únicas y explicitas con las dificultades para hacer cualquier tipo de valoración medible, plantear estrategias realmente explicitas y poder separar la formulación de la ejecución.

- Adaptativo: la formación estratégica interactúa entre un ambiente dinámico y burocrático y durante periodos se puede seguir "regularidades diferenciadas" que ayudan a la comprensión general del proceso.

- Estrategias realizadas e intencionadas.

- La estrategia, como el conjunto de comportamientos consistentes y el cambio estratégico como: "la respuesta de la organización al cambio ambiental, restringido por el momentum de la burocracia y acelerado o retrasado por el liderazgo" (Mintzberg, 1978).

En definitiva, una manera de percibir patrones está asociada a identificar acciones realizadas y verificar si estas acciones se repiten de manera consistente en diferentes periodos, lo que conduce a considerar la formación de dichos patrones

\section{Metodología}

La metodología consistió, primero, en la recolección de fuentes bibliográficas con información de la compañía, cuya búsqueda se centró en recortes de periódicos, noticias, informes de gestión encontradas en la página principal de la organización ${ }^{15}$, así como en su revista corporativa ${ }^{16}$ (Anexo 1 ).

En segunda instancia, con la información del marco teórico, se realizó un análisis detallado año a año con base en algunos tópicos, los cuales eran un patrón repetitivo anualmente según la información mostrada en los informes públicos, y que permitió hacer un comparativo de los cambios evidenciados. Para esto se siguieron las dimensiones o segmentos para el análisis estratégico, que se presentan a continuación:

- Responsabilidad social.

- Desarrollo de infraestructura.

- Consolidación del negocio.

- Premios y logros.

- Cantidad de clientes y estados financieros.

- Productos por unidad de negocio.

- Retos.

- Otros aspectos generales.

La recopilación anterior permitió que el análisis anual sirviera para la identificación de patrones de acuerdo a lo propuesto por Mintzberg, identificando aquellas variables de una estrategia deliberada que se realiza por varios periodos.

Así, con este procedimiento se buscó articular el sistema de valor, el análisis industrial y la posición en el mercado de la compañía y para así poder identificar los patrones en la toma de decisiones a través de los resultados, informes e información pública encontrada.

15 Incluye la presentación anual de los resultados entregados ante el Concejo de Medellín.

16 Revista mensual UNETE. 


\section{Discusión de resultados}

Las acciones realizadas anualmente se sintetizan en los siguientes tópicos:

- Responsabilidad social: son aquellas acciones para el mejoramiento de la sociedad. Durante los dos primeros años, se hace mayor énfasis sobre aquellos productos masivos como teléfonos públicos, de igual forma comienzan las bases de Medellín Digital el cual continua hasta el 2011. Servicios innovadores como la tarjeta EPM y planes sociales se extienden hasta el 2012 y a finales del 2013 obtiene el reconocimiento a Ciudades Inteligentes UNE.

- Desarrollo en infraestructura: como aquellos aportes tecnológicos realizados para optimizar la red o generar nuevos productos. En el 2006 comienza una fuerte inyección de capital para ampliar infraestructura y plataformas de los diferentes servicios con mayor énfasis inicialmente sobre productos masivos. En el 2008 una vez se consolida la división de cada UEN, se comienza con los aportes necesarios para infraestructura de productos específicos y con mejores características, dando mayor cobertura a nivel nacional. En el 2011 cuando se comienza con el montaje de infraestructura para el proyecto 4G y para los años 2012 y 2013 se continúan con los proyectos de expansión y ampliación de la red a nivel nacional.

- La consolidación del negocio: las acciones realizadas en cuanto a la conformación de la organización, alianzas estratégicas e integraciones. Este punto cobra principal fuerza sobre toda la estructura de la compañía, ya que finalmente especifica claramente las alianzas e integraciones con otras empresas, así como la conformación de las unidades de negocio. En el 2008 la conformación del SGI (sistema de gestión integral) es parte fundamental para estructurar los procesos y la administración de la empresa, sistema que se ha ido consolidando hasta el 2012. Finalmente durante el 2013 comienza el proceso de integración con una empresa internacional.
- Premios y Logros: a través de las cuales la empresa tuvo algún reconocimiento en entidades con dicho propósito, así como las certificaciones obtenidas a lo largo del desarrollo de la compañía. Premios con la calificación de riesgo AAA, mejor proveedor de servicio de internet en Latinoamérica, Anfitrión y aliado tecnológico de diferentes proyectos sector gobierno, implementación de normas y resoluciones emitidas por la $\mathrm{CRC}$ y otros proyectos, fueron decisivos para continuar con los planes propuestos desde el 2006.

- Productos por negocio: desarrollados de acuerdo a la conformación de las unidades de negocio, y según el nicho de mercado. Cada unidad de negocio ha creado sus propias estrategias de mercado, según las necesidades de consumo, generando nuevos servicios y productos adaptables al modelo diseñado.

- Clientes y estados financieros: mostrando el crecimiento constante sobre el número de servicios y generalizando sobre los productos. De igual forma ilustra aquellos dos ítems financieros nombrados sobre los estados contables de la compañía: EBITDA y los ingresos operacionales.

- Retos: a través de los años se tiene como aquellos sobresalientes la consolidación de la empresa y la extensión de los productos y servicios a nivel nacional e incluso internacional, tomando como base la optimización de recursos y disminución de costos en todos los procesos, manteniendo los estándares y certificaciones ya obtenidas en periodos anteriores.

Al consolidar estos ítems y hacer un comparativo con aquellas estrategias más significativas que tienen principal incidencia durante los años en estudio, surge el siguiente gráfico, el cual describe la estratega de la organización (véase ilustración 6).

Con base en lo mostrado en la Ilistración 6 , los dos primeros años de conformación de la empresa coinciden con la teoría de Ansoff mencionada en el sección 2 de este documento, en donde con estrategias de penetración al mercado, UNE busca su posicionamiento 
Ilustración 6. Estrategia organizacional años 2006 a $2012^{17}$

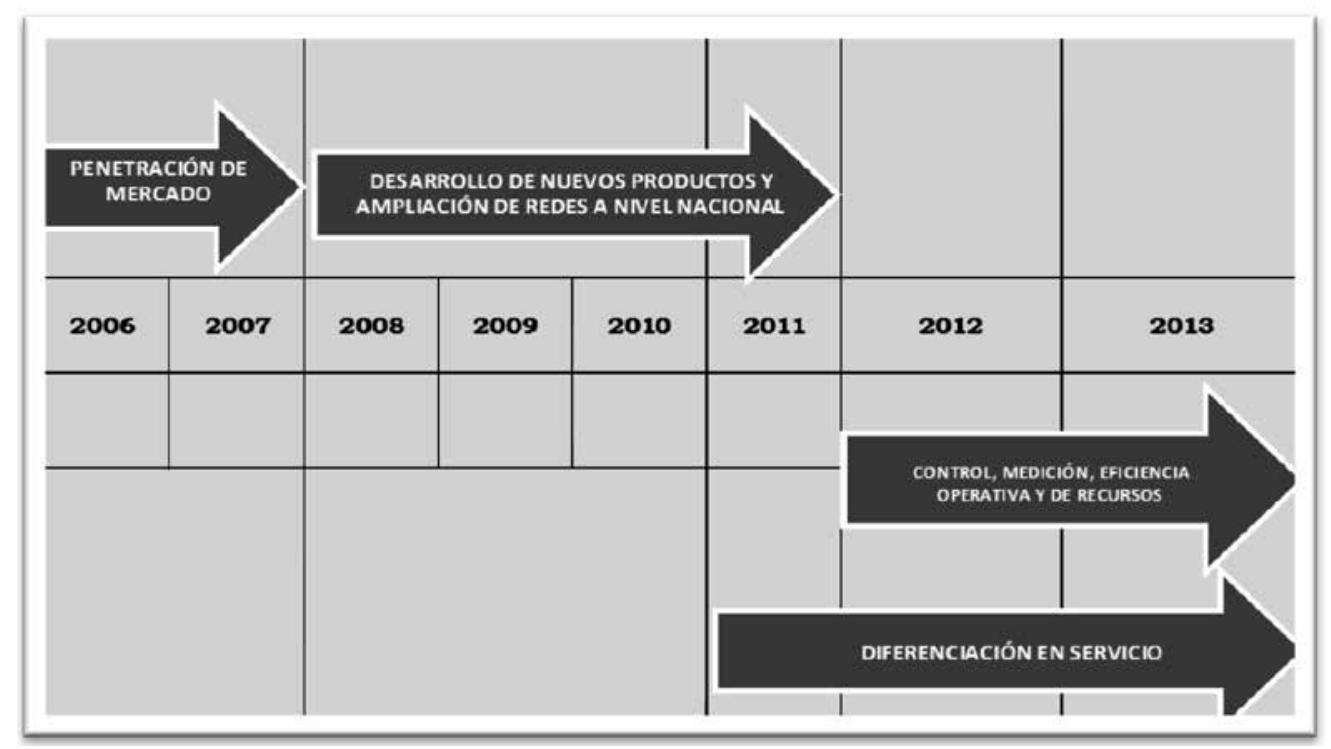

en el sector, formando unidades estratégicas de negocio (hogares, Pymes, corporativo e internacional).

La diversificación para Ansoff (1957) está relacionada con el cambio en las características de la línea de compañía, producto o mercado. Esto se ve claramente reflejado desde el año 2008 al año 2011 en donde la expansión a la red nacional se convierte en uno de los principales objetivos de la compañía, así como encontrar los productos específicos según el tipo de mercado.

Un comparativo entre lo planteado por Ansoff y lo hallado en UNE se muestra en la Tabla 1.

Tabla 1. Ansoff vs. UNE ${ }^{18}$

\begin{tabular}{|c|l|c|}
\hline & \multicolumn{1}{|c|}{ Producto existente } & \multicolumn{1}{c|}{ Penetración de mercado } \\
\hline $\begin{array}{c}\text { Mercado } \\
\text { existente }\end{array}$ & $\begin{array}{l}\text { Se da principalmente en los años 2006 y 2007, en la ciudad nuevo } \\
\text { de Medellín. En este periodo también se consolida la integra- } \\
\text { ción ya realizada entre Emtelco, Orbitel y Une. Cuyo principal } \\
\text { objetivo es consolidar la marca. }\end{array}$ & $\begin{array}{c}\text { Desarrollo de producto } \\
\text { El sector de las telecomunicaciones es altamente cambiante y exigen- } \\
\text { te, lo que hizo que se desarrollaran nuevas ofertas, productos y servicios } \\
(2008 \text { - 2011.) }\end{array}$ \\
\hline $\begin{array}{c}\text { Mercado } \\
\text { nuevo }\end{array}$ & $\begin{array}{l}\text { Desarrollo de mercado } \\
\text { Desde la conformación de la expansión de red a nivel nacional e internacional. En } \\
\text { los inicios del 2008 hasta 2011 se comienza con toda una } \\
\text { estrategia de ampliación de redes ofreciendo inicialmente los } \\
\text { productos que en ese momento se habían consolidado en las } \\
\text { estrategias de las unidades de negocio. }\end{array}$ & $\begin{array}{l}\text { Cada región y sector tiene una necesidad fundamental de productos y ser- } \\
\text { vicios, lo que incita a realizar un estudio estratégico, identificando dichas } \\
\text { pautas que conllevaron finalmente a un mercado nuevo con expansión de } \\
\text { red nacional e internacional y cubriendo las necesidades claras de cada } \\
\text { sector (2008 - 2011). }\end{array}$ \\
\hline
\end{tabular}

17 Fuente: Elaboración propia.

18 Fuente: Elaboración propia. 
Sin embargo, para Ansoff según la Tabla 1, la empresa está en continuo crecimiento y es claro que después de su conformación, su principal objetivo es hacer mercado. Pero recordemos que Porter (1990, 1991) difiere de Ansoff (1957), ya que la inversión tecnológica realizada tiene que buscar ser recuperada lo suficientemente rápido, aplicándola al mercado específico, que para UNE dicha inversión ha sido alta en sus estrategias de expansión

Porter (1991) de igual forma resalta la confrontación de servicios sustitutos ofrecidos por sus competidores, los cuales en esta investigación han sido participativos desde el 2008 en adelante realizando alianzas e integraciones importantes. Allí es donde las 5 fuerzas de Porter se traducen en UNE de la siguiente forma:

- Poder negociador de los compradores: los compradores en este caso están distribuidos en todas las unidades de negocio (UEN) propuestas: Hogares, Pymes, Corporativos, Nuevos mercados e Internacional. Los cuales contratan diferentes productos de Datos, Voz e Internet, en las modalidades propuestas según la estrategia de cada UEN y se ven demarcadas durante 4 años de su conformación (2008 - 2011).

- Poder negociador de los proveedores: UNE cuenta con diversos proveedores en cuanto a su infraestructura de plataforma o equipos de usuario final, los cuales deben cumplir los estándares a nivel internacional, así como superar las diversas pruebas de compatibilidad con la oferta actual de la compañía, validando los niveles de calidad y servicio.

- Amenaza de entrada de nuevos competidores: los últimos años se han formado alianzas e integraciones estratégicas con nuevos competidores más robustos, lo que al entrar en ofertas para el mercado que actualmente tiene UNE, puede convertirse para estos competidores en diversos problemas de falta de experiencia o atención al cliente. En UNE el principal impacto se identifica directamente en la disminución de ventas.
- Amenaza de ingreso de productos sustitutos: como ya se ha mencionado anteriormente, el sector de las telecomunicaciones es bastante cambiante y activo, lo que conlleva a estar siempre alineados con las nuevas tecnologías y listos con la infraestructura necesaria para soportarla. Durante la investigación realizada, se puede identificar claramente el desarrollo tecnológico realizado desde el 2008 a la fecha, así como las diferentes ofertas y servicios para cada nicho de mercado.

- Rivalidad interna de la industria entre competidores: La rivalidad que afronta UNE está marcada por la oferta de sus competidores en el mismo tipo de producto y con bajos precios. Sin embargo la compañía le apuesta a la diferenciación en servicio, estrategia que viene utilizando desde el 2011, convirtiendo la atención al cliente en experiencias memorables y positivas.

Ahora bien, Montoya (2010) menciona las razones que según Porter marcan la posición competitiva en el sector con base en el análisis realizado de las 5 fuerzas:

- Solución al problema de agencia: aunque cada UEN tiene su estrategia definida, siempre UNE ha dejado claro cuál es su reto a nivel de compañía año tras año, lo que la hace integradora en las actividades y definiciones de cada unidad de negocio.

- Armonización de elementos externos e internos: UNE ha sido consciente del entorno en el que se encuentra, y así mismo ha desarrollado sus estrategias para competir en el sector.

- Creación de competencias distintivas: una estrategia de retención y fidelización fue diseñada como oferta de valor para competir en el mercado y fue conocida como Diferencial en Servicio desde el 2011 afianzando el posicionamiento competitivo de la compañía. 
De acuerdo a las definiciones dadas por Porter (1980, 1990, 1991) la matriz de posicionamiento ${ }^{19}$ para UNE podría estar dada actualmente por una propuesta diferenciadora, ya que aun tiene que resolver el problema de recuperar la inversión frente a la inversión tecnológica realizada.

Empero ¿qué pasa en momentos de innovación o cambio?, precisamente Mintzberg (1978) es quien busca respuesta a este cuestionamiento contrario a Porter (1991), identificando patrones en la toma de decisiones. Al seguir su metodología ${ }^{20}$ se encuentra que:

- Colección de datos básicos: en el capítulo 3 se realiza una recopilación completa de los eventos y decisiones tomadas en la compañía que pueden marcar algún patrón de estudio. Dicha información fue extraída de la revista Unete, informes de gestión, periódicos y noticias en general.

- Interferencia de las estrategias y períodos de cambio: se realizó una agrupación de los prin- cipales tópicos de estudio vs. el comparativo anual, extrayendo aquellos factores de mayor significado, los cuales se pueden encontrar al detalle en el Anexo 2.

- Análisis intensivo de los periodos de cambio: dichos periodos son los que muestran la estrategia realizada: i) penetración de mercado; ii) desarrollo de nuevos productos y ampliación de redes a nivel nacional; iii) diferenciación en servicio; y iv) control, medición, eficiencia operativa y de recursos (lo que se nombrara a partir de este momento como disciplinas de valor).

Con base en lo anterior y en el modelo de ciclo de vida propuesto por Mintzberg (1984) se plantea la Ilustración 7.

En la Ilustración 7 se logra identificar claramente cada uno de los ciclos propuestos por la compañía:

- Fase de formación: con la conformación de la empresa, integración, etc.

Ilustración 7. Ciclo de vida ${ }^{21}$

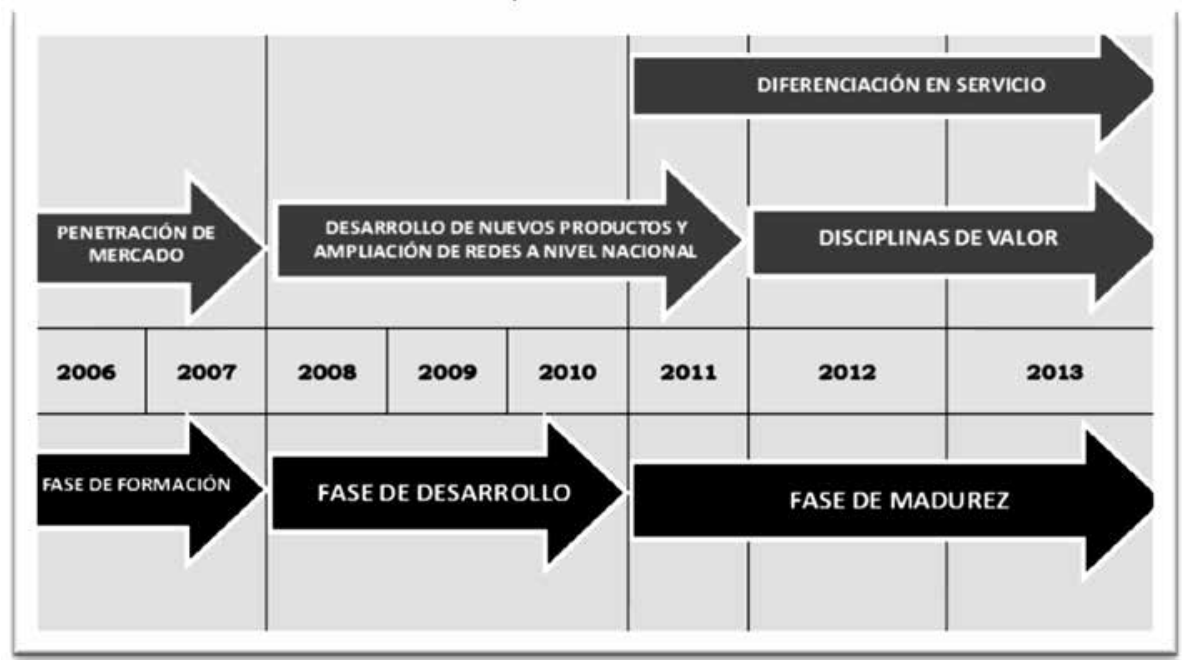

19 Recordar que la matriz de posicionamiento para Porter consiste en: Convertirse en el líder absoluto en costos sobre su industria. Tener una propuesta diferenciadora. O utilizar una combinación entre las dos anteriores: calidad/servicio vs precio

20 En el apartado 2-3 se explica la metodología de Mintzberg, para mayor referenciación.

21 Fuente: Elaboración propia. 
- Fase de desarrollo: adquisición de nuevos productos, mercados, tecnologías, etc.

- Fase de madurez: eficiencia y optimización de lo que ya se tiene.

- Fase de declinación: ciclo para renovar la organización y buscar cambios estratégicos.

Si se compara algunas de las definiciones de estrategia dadas por Montoya (2010) con algún momento específico en la compañía se tiene:

- Equivalente a un plan, que para la organización pudo estar dada desde su conformación, tomando ventaja de las acciones que fueron desarrolladas a lo largo de su consolidación como empresa en el sector.

- Un patrón que se puede identificar en cada fase de los ciclos de vida. Es decir diversos patrones en cada periodo:

- Un patrón de desarrollo e integración

- Un patrón de nuevas tecnologías y expansión.

- Un patrón de diferenciación según la exigencia del mercado en ese instante de tiempo.

- Un patrón de optimización de tiempo y recursos.

- Como una posición frente a su entorno y la relación con sus competidores, de acuerdo a las acciones de control tomadas como participación en el mercado. Algunas de estas acciones, posiblemente planeadas o tomadas de acuerdo a los comportamientos tanto de consumidores como de competidores en cada región

Finalmente, la formación estratégica en el campo administrativo estudiado por Mintzberg (1984) y mencionado por Montoya (2010), se puede dar:

- Planeación y posicionamiento: dadas finalmente en los años 2011 - 2012 y 2013, con estrategias explicitas que separan claramente la formulación de la ejecución y se concentra en esta última.
- Adaptativo: no tiene mayor incidencia en la estrategia de la empresa, aunque en algunos instantes de tiempo logra ser dinámica, no se logran identificar "regularidades diferenciadas".

- Estrategias realizadas e intencionadas: identificables a lo largo de la investigación.

Cumpliendo claramente con la estrategia, como conjunto de comportamientos consistentes y el cambio estratégico como respuesta al de cambio ambiental descrito en el Anexo 2.

\section{Conclusiones}

Después de indagar en los principales eventos y noticias que han marcado la historia de la compañía, es bastante enriquecedor encontrar aquellos puntos de conexión entre lo expuesto por los autores y las estrategias utilizadas, permitiendo a su vez identificar dichas estrategias utilizadas en su conformación.

A continuación se muestran las conclusiones referentes a cada autor descrito, seguido de su relación entre la investigación y la teoría:

- Se presenta una redefinición de la estrategia en el 2008, una vez se da la diversificación en productos y servicios propuesta por Ansoff (1957) en UNE, ayudando a cumplir los objetivos propuestos en la MEGA de la organización.

- En el 2008 comienza toda una estrategia de posicionamiento competitivo propuesto y estudiado anteriormente con Porter (1980, 1990, 1991), analizando como su desempeño financiero ha crecido, mantenido o disminuido en el tiempo y las implicaciones que ha tenido en la toma de decisiones.

- Esta investigación parte del modelo operacional con el estudio de los procesos realizados durante su periodo de conformación. El análisis de las capacidades y recursos que han marcado las decisiones estratégicas de la compañía, muestran como resultado, la finalidad de una estrategia, según lo propuesto por Montoya (2010). 
- El análisis del estudio de la conformación de UNE fue realizado sobre fenómenos tangibles propuestos en la sección 2, lo que Mintzberg (1978) llamó flujo de decisiones, y las estrategias mostradas fueron los patrones observados en dichos flujos durante los periodos descritos en las tablas mostradas.

Una manera de percibir patrones está asociada a identificar acciones realizadas y verificar si estas acciones se repiten de manera consistente en diferentes periodos, lo que conduce a considerar la formación de patrones.

- En los años de estudio presentados en este trabajo, no se percibe ninguna estrategia emergente, por el contrario, todo lo que se realiza tiene cierta coherencia en el tiempo que de alguna forma presenta todo un despliegue de la estrategia en UNE como un ejercicio deliberado.

- Los negocios de tecnología tienen una rápida velocidad de cambio y la obsolescencia tecnológica puede llegar a ser muy alta, tal y como se logra identificar en los ciclos de vida de producto mostrados, los cuales de alguna manera permanecen en constante cambio y con nuevas alternativas innovadoras, tales como LTE y GPON.

Como propuesta para trabajos futuros, sería interesante lograr identificar estos mismos patrones y flujos de decisiones, para identificar las estrategias deliberadas o emergentes que finalizaron en una fusión entre empresas, analizando aquellas que finalmente fueron absorbidas por UNE y así mismo identificar aquellos aspectos futuros de integración.

Esta investigación en últimas presentó una metodología para identificar patrones que hablen de la formación de la estrategia, siendo también de gran interés para trabajos futuros proponer otras formas de hacerlo, además de los mecanismos con sus resultados.

\section{Referencias}

Ansoff, H. (1957). Strategies por diversification. En: Harvard Business Review, 35(5): 113 - 124.

Ansoff, H., Declerk, R. \& Hayes, R. (1983). El planteamiento estratégico, "Nueva tendencia de la Administración". Ed. Trillas, México D.F.

Ansoff, H. \& McDonnell, E. (1990). Implanting strategic management. Prentice Hall Europe.

Martinet, A. (2010). Strategic planning, strategic management, strategic foresight: the seminal work of H. Igor Ansoff. En: Technological Forecasting \& Social Change, 77(9): 1485-1487.

Mintzberg, H. (1978). Patterns in strategy formation. En: Managemente Science, XXIV(9): 934-948.

Mintzberg, H. (1984). Power and organization life cycles. En: The Academy of Management Review, 9(2): 207 - 224.

Mintzberg, H. (1987). The strategy concept I: five ps for strategy. En: California Management Review, 30(1): 11-24.

Mintzberg, H. (1990). The design school: reconsidering the basic premises of strategic management. En: Strategic Management Journal, 11(3): 171-195.

Mintzberg, H. (2009). Tracking strategies: toward a general theory of strategy formation. New York, NY: Oxford University Press.

Mintzberg, H. (2012). Developing naturally: from management to organization to society to selve. En: Snook, S., Nohria, N. \& Khurana, R. (eds.) The handbook for teaching leadership. Thousand Oaks, CA: Sage.

Montoya, I. (2009). La formación de la estrategia en Mintzberg y las posibilidades de su aportación para el futuro. En: Reista Facultad de Ciencias Económicas, Universidad Militar Nueva Granada, XVII(2): 23-44.

Montoya, I. (2010). Tesis de grado, Doctorado en Ciencias Económicas. Bogotá: Universidad Nacional de Colomba.

Montoya, I. \& León, E. (2004). Los ciclos de generacion de competencias y su aplicación en las organizaciones. Innovar No 24, 9-27.

Montoya, I. \& Montoya, L. (2003). El direccionamiento estratégico y su aplicación en los sistemas complejos y en la gerencia ambiental. En: Innovar, 13(21): 81-104.

Moussetis, R. (2011). How Ansoff interfaces with both the planning and learning schools of thought in strategy. En: Journal of Management History, 17(1): 102-125.

Ortiz, M. (2013). La programación lineal entera. Uso de criterios cualitativos en la función objetivo. Caso: número de taquillas de paso para pago de servicios públicos. En: Espacios, 34 (8), 1-11.

Porter, M. (1980). Competitive strategy: techniques for analyzing industries and competitors. Free Press.

Porter, M. (1990). Competitive advantage of nations. Harvard Business Review.

Porter, M. (1991). Towards a dynamic theory of strategy. En: Strategic Managment Journal, 12: 95-117.

Porter, M. \& Kramer, M. (2011). La creación de valor compartido. Harvard Business Review America Latina 


\section{ANEXOS}

Anexo 1. Notas de prensa y documentos corporativos ${ }^{1}$

Alvarez, V. (mayo 9 de 2013). El tiempo. Recuperado de: http://www.eltiempo.com/colombia/medellin/ARTICULO-WEB-NEW_NOTA_INTERIOR-12787902.html

Eichmann, M. (mayo 7 de 2013). El Espectador. Recuperado de: http://www.elespectador.com/noticias/nacional/articulo-420660-une-dice-haypresiones-indebidas-proyecto-de-fusion-millicom

El Colombiano (abril 16 de 2013). El Colombiano. Recuperado de: http://m.elcolombiano.com/article/139497

EPM, D. d. (2007). Edicion Julio. Revista Unete, 3,4.

Gallo, G. (agosto de 2011). El Colombiano. Obtenido de http://www.elcolombiano.com/BancoConocimiento/U/une_bajo_tarifas_de_sus_servicios/ une bajo tarifas de sus servicios.asp

Gómez, L. (octubre de 2011). Portafolio. Obtenido de http://www.portafolio.co/negocios/etb-une-y-emcali-estudian-posible-union

Medellín, R. (abril de 2012). El Tiempo. Obtenido de http://www.eltiempo.com/colombia/medellin/ARTICULO-WEB-NEW NOTA INTERIOR-11649421.html

Portafolio (marzo de 2011). Obtenido de http://www.portafolio.co/detalle archivo/MAM-4421865

Portafolio (febrero de 2012). Obtenido de http://www.portafolio.co/negocios/\%E2\%80\%98piden-7-veces-mas-transmitir-el-futbol\%E2\%80\%99-une

Portafolio (enero de 2012). Obtenido de http://www.portafolio.co/negocios/nombran-marc-eichmann-como-nuevo-presidente-une

Redaccion El Colombiano (agosto de 2012). El Colombiano. Obtenido de: http://diarioadn.co/medell\%C3\%ADn/mi-ciudad/contin\%C3\%BAandenuncias-sobre-p\%C3\%A9rdidas-y-altos-salarios-en-une-1.13779

Rojas, J. (junio de 2012). El Colombiano. Obtenido de: http://www.elcolombiano.com/BancoConocimiento/U/une_apunta_a_200_mil_clientes_ con internet $4 \mathrm{~g} / \mathrm{une}$ apunta a 200 mil clientes con internet $4 \mathrm{~g} . \mathrm{asp}$

Sánchez, 0. (2012). El tiempo. Obtenido de: http://m.eltiempo.com/colombia/medellin/denuncia-por-corrupcin-en-une/11962951

Teleantioquia Noticias. (agosto de 2012). Obtenido de: http://noticias.teleantioquia.com.co/es/videos/valle-de-aburra/20120715/contraloria-medeIlin-destaco-los-manejos-financieros-une/5235.shtml

UNE (2006 - 2012). Une.com.co. Obtenido de http://www.une.com.co/accionistas-e-inversionistas/asamblea-de-accionistas

UNE (2008). Informe de Gestión. Medellín.

UNE (2009). Informe de Gestión. Medellín.

UNE (2010). Informe de Gestion. Medellín.

UNE (2011). Informe de Gestión. Medellín.

UNE (2012). Une.com.co. Obtenido de: http://www.une.com.co/images/documentos/Inversionistas/informe_gestion_sostenibilidad-2012.pdf

UNE (2013). Historia. Obtenido de: http://www.une.com.co/pymes/foro/2-bienvenidos/141-logo-firmy-budowlanej.html

UNE (marzo de 2013). Une.com.co. Obtenido de: http://www.une.com.co/compania/informacion-corporativa/informacion-general

UNE, D. d. (2007). Edición Agosto. Revista Unete, 4,5.

UNE, D. d. (2007). Edición Diciembre. Revista Unete, 2,3

UNE, D. d. (2007). Edición Octubre. Revista Unete, 3,16.

UNE, D. d. (2008). Edición Agosto. Revista Unete, 7,8-12,15.

UNE, D. d. (2008). Edición Diciembre. Revista Unete, 2.

UNE, D. d. (2008). Edición Julio. Revista Unete, 6,7,18.

UNE, D. d. (2008). Edición Junio. Revista Unete, 8-10,12,13.

UNE, D. d. (2008). Edición Marzo. Revista Unete, 2,14,15.

UNE, D. d. (2008). Edición Mayo. Revista Unete, 2,7,16,17,18.

UNE, D. d. (2008). Edición Noviembre. Revista Unete, 3,4.

UNE, D. d. (2008). Edición Octubre. Revista Unete, 3.

UNE, D. d. (2008). Edición Septiembre. Revista Unete, 2,8-9, 15,18.

UNE, D. d. (2009). Edición Abril. Revista Unete, 3,7,11,12.

UNE, D. d. (2009). Edición Agosto. Revista Unete, 6,12,13.

UNE, D. d. (2009). Edición Diciembre. Revista Unete, 2-18.

UNE, D. d. (2009). Edición Junio. Revista Unete, 3.

UNE, D. d. (2009). Edición Marzo. Revista Unete, 6,7.

UNE, D. d. (2009). Edición Mayo. Revista Unete, 3.

UNE, D. d. (2009). Edición Septiembre. Revista Unete, 3, 7, 16,17.

UNE, D. d. (2010). Edición Agosto. Revista Unete, 10-11.

1 Fuente: Elaboración propia. Selección de notas de prensa y documentos corporativos de UNE EPM Telecomunicaciones en el periodo 2006-2013. 
UNE, D. d. (2010). Edición Enero. Revista Unete, 2,4,10.

UNE, D. d. (2010). Edición Julio. Revista Unete, 3,8-9, 16-18.

UNE, D. d. (2010). Edición Junio. Revista Unete, 12-13.

UNE, D. d. (2010). Edición Marzo. Revista Unete, 5-7,10-11.

UNE, D. d. (2010). Edición Mayo. Revista Unete, 17,18.

UNE, D. d. (2010). Edición Noviembre. Revista Unete, 3-4.

UNE, D. d. (2010). Edición Octubre. Revista Unete, 2,3,6-7.

UNE, D. d. (2010). Edición Septiembre. Revista Unete, 3,7-10, 12-13.

UNE, D. d. (2011). Edición Abril. Revista Unete, 14-15, 16-17.

UNE, D. d. (2011). Edición Agosto. Revista Unete, 16.

UNE, D. d. (2011). Edición Diciembre. Revista Unete, 4-5, 16-17, 26-27.

UNE, D. d. (2011). Edición Enero. Revista Unete, 2-4.

UNE, D. d. (2011). Edición Julio. Revista Unete, 2-6,16-17.

UNE, D. d. (2011). Edición Marzo. Revista Unete, 3.

UNE, D. d. (2011). Edición Mayo. Revista Unete, 2,3,4,7-9.

UNE, D. d. (2011). Edición Octubre. Revista Unete , 4-5.

UNE, D. d. (2012). Edición Abril. Revista Unete, 2.

UNE, D. d. (2012). Edición Diciembre. Revista Unete, 10-11.

UNE, D. d. (2012). Edición Febrero. Revista Unete, 3-9, 12-13.

UNE, D. d. (2012). Edición Noviembre. Revista Unete, 3.

UNE, D. d. (2012). Edición Septiembre. Revista Unete, 2-4,12. 
Anexo 2. Cuadro anual y resumen por tópico²

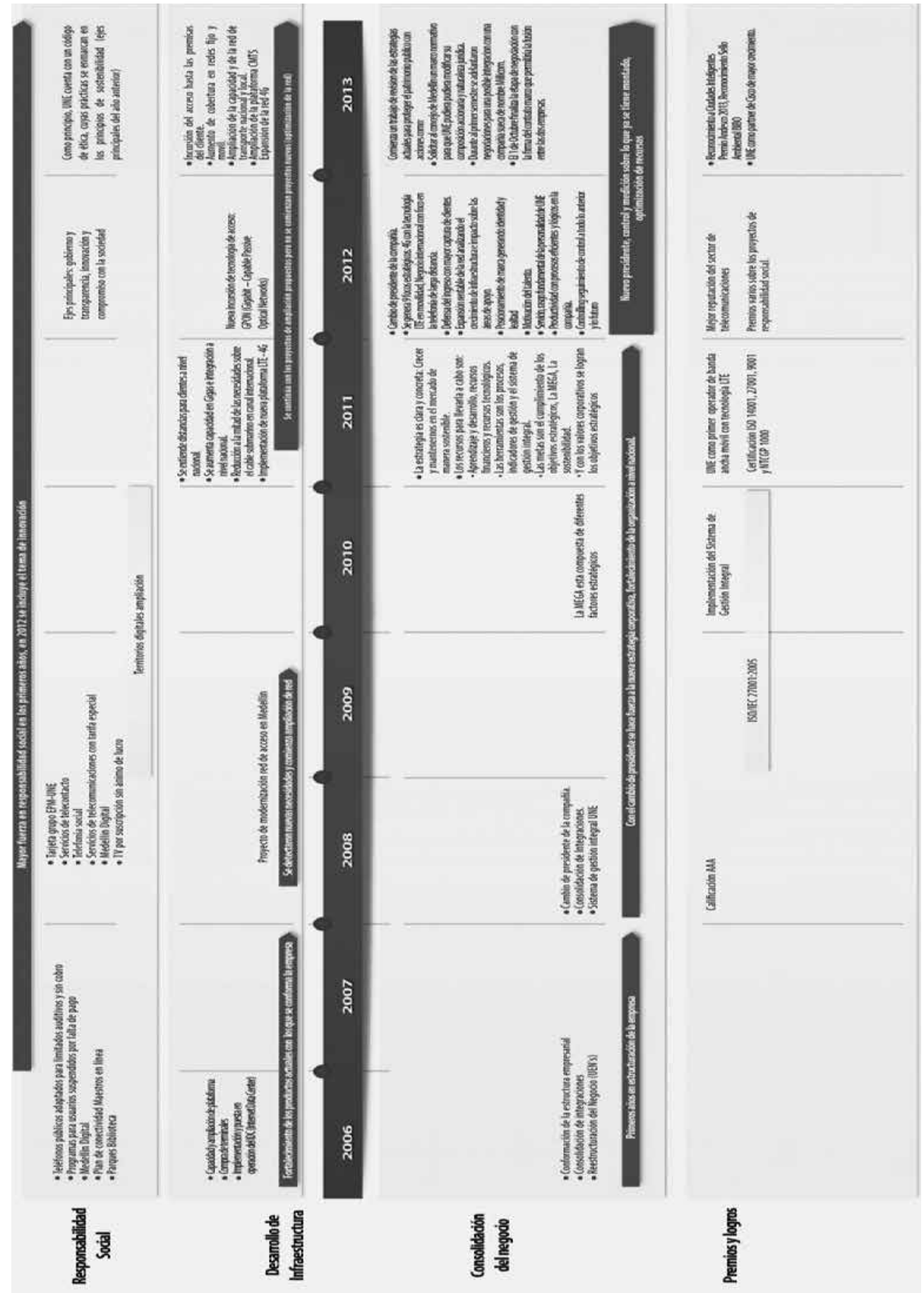

Fuente: UNE EPM Telecomunicaciones. 

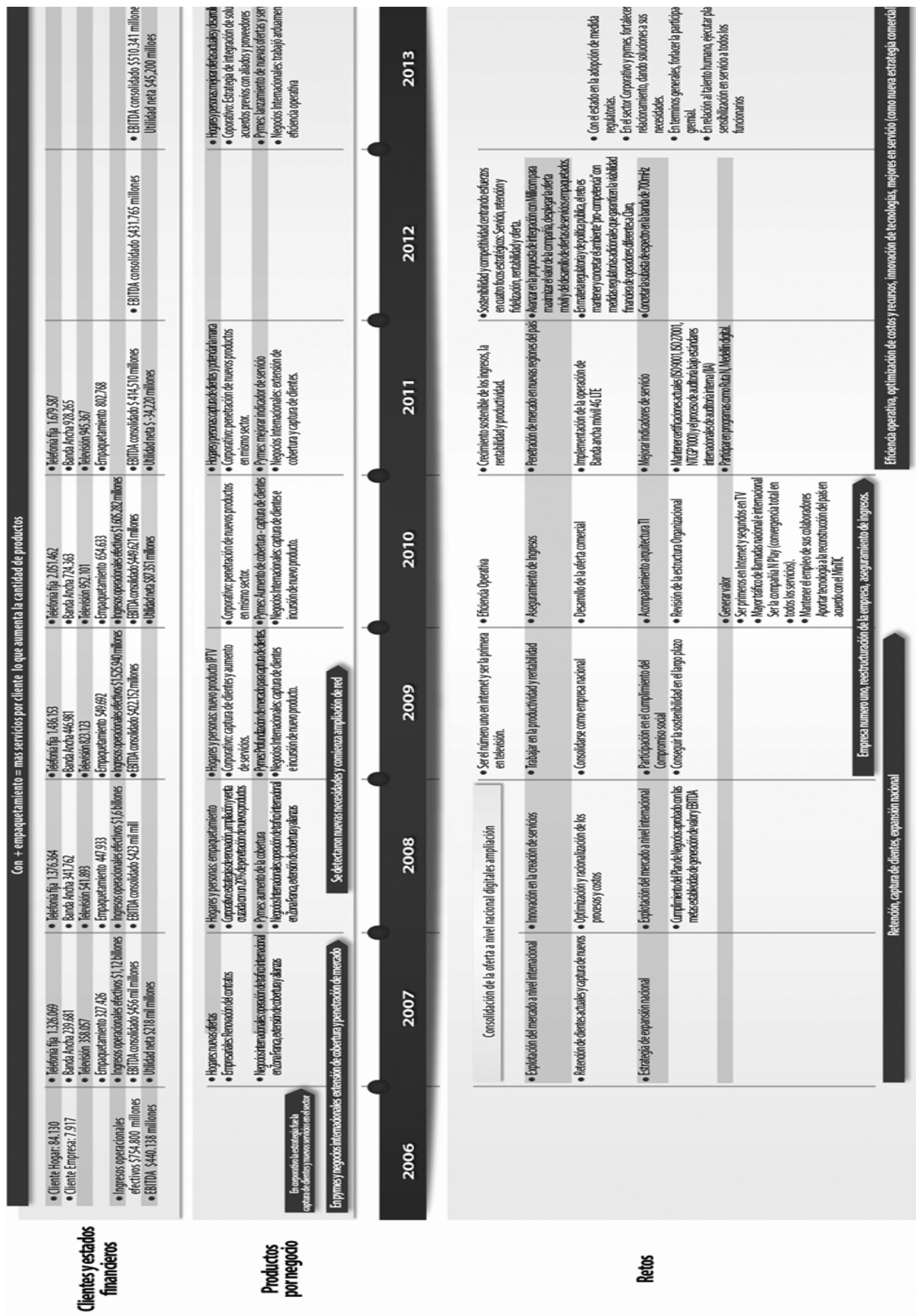